\title{
Neutron Irradiation Induced Amorphization of Uranium Silicides
}

\author{
J. W. Richardson, Jra , R. C. Birtcher ${ }^{\mathrm{b}}$, S.-K. Chan ${ }^{\mathrm{b}}$ \\ ${ }^{\mathrm{a}}$ Intense Pulsed Neutron Source (IPNS) and ${ }^{\mathrm{b}}$ Materials Science (MSD) Divisions, Argonne \\ National Laboratory, Argonne, IL 60439 USA
}

\begin{abstract}
The submitted manuscript has been authored by a contractor of the U. S. Government under contract W-31-109-ENG-38. Accordingly, the U. S. Government retains a nonexclusive, royalty-free license to publish or reproduce the published form of this contribution, or allow others to do so, for U.S. Government purposes.
\end{abstract}

To be published in Physica B

*Work supported by U. S. Department of Energy, BES, contract No. W-31-109-ENG-38 


\section{DISCLAIMER}

This report was prepared as an account of work sponsored by an agency of the United States Government. Neither the United States Government nor any agency thereof, nor any of their employees, make any warranty, express or implied, or assumes any legal liability or responsibility for the accuracy, completeness, or usefulness of any information, apparatus, product, or process disclosed, or represents that its use would not infringe privately owned rights. Reference herein to any specific conmercial product, process, or service by trade name, trademark, manufacturer, or otherwise does not necessarily constitute or imply its endorsement, recommendation, or favoring by the United States Government or any agency thereof. The views and opinions of authors expressed herein do not necessarily state or reflect those of the United States Government or any agency thereof. 


\section{DISClamiar}

Portions of this document may be illegible in electronic image products. Images are produced from the best available original docoment. 


\title{
neutron irradiation induced amorphization of uranium silicides
}

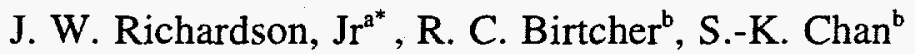 \\ ${ }^{a}$ Intense Pulsed Neutron Source (IPNS) and ${ }^{\mathrm{b}}$ Materials Science (MSD) Divisions, Argonne \\ National Laboratory, Argonne, IL 60439 USA
}

\begin{abstract}
Time-of-flight neutron powder diffraction studies of incrementally neutron-irradiated $\mathrm{U}_{3} \mathrm{Si}$ and $\mathrm{U}_{3} \mathrm{Si}_{2}$ have revealed details of progressive amorphization of bulk materials, crystalline transformation prior to amorphization, elastic strain and diffuse scattering resulting from scattering interference between crystalline and amorphous fractions. Density differences between amorphous and crystalline fractions give rise, respectively, to tensile and compressive strain in $\mathrm{U}_{3} \mathrm{Si}$ and $\mathrm{U}_{3} \mathrm{Si}_{2}$. Diffuse scattering associated with each Bragg peak shows crystallographic direction-dependent variation both in magnitude and displacement (relative to the Bragg position). A theoretical model describing this behavior relates the size of the amorphous zones, and the magnitude and displacement of the diffuse scattering contribution. After complete amorphization of $\mathrm{U}_{3} \mathrm{Si}$ and $\mathrm{U}_{3} \mathrm{Si}_{2}$, anneals to progressively higher temperatures generate gradual evolution of the short- to intermediaterange amorphous structures prior to re-crystallization.
\end{abstract}

Keywords - neutron irradiation, amorphization, powder diffraction

\footnotetext{
* Corresponding author, E-mail: JWRichardson@anl.gov, Fax: (630) 252-4163
} 


\section{Introduction}

High density intermetallic alloys of uranium and silicon have been considered for use in high power-density nuclear applications and lower power-density, reduced enrichment applications. $\mathrm{U}_{3} \mathrm{Si}$ and $\mathrm{U}_{3} \mathrm{Si}_{2}$ have received the most attention as reactor fuels. A fundamental stumbling block to the use of $\mathrm{U}_{3} \mathrm{Si}$ in such applications is catastrophic swelling, occurring at high fuel loadings, due to plastic flow of amorphous $\mathrm{U}_{3} \mathrm{Si}$ during irradiation $[1,2]$.

Because of this swelling in $\mathrm{U}_{3} \mathrm{Si}$, emphasis shifted to $\mathrm{U}_{3} \mathrm{Si}_{2}$. Although scant data regarding the irradiation behavior of $\mathrm{U}_{3} \mathrm{Si}_{2}$ exist [see references in ref. 4], it also becomes amorphous under ion and neutron irradiation [3]. Such amorphization raises concern about potential mechanical instability in $\mathrm{U}_{3} \mathrm{Si}_{2}$ and motivates this work. This study of the irradiation behavior of $\mathrm{U}_{3} \mathrm{Si}$ and $\mathrm{U}_{3} \mathrm{Si}_{2}$, synopsized here and reported in detail elsewhere [4,5], was carried out as part of the reactor fuel development program for the Advanced Neutron Source (ANS).

\section{Discussion}

This work utilized high resolution neutron powder diffraction (NPD), on the General Purpose Powder Diffractometer (GPPD) [6] at IPNS, following neutron irradiation [7] and in situ transmission electron microscopy with electron diffraction during $\mathrm{Kr}$ ion irradiation, using Argonne's HVEM facility [8]. Ion irradiation provides rapid damage accumulation, in thin specimens, where atomic scale structures of specimens can readily be determined by electron diffraction. Quantitative details of the amorphization, though, are not easily obtained by electron diffraction. High resolution NPD, on the other hand, yields precise crystallographic and phase information. NPD experiments are especially valuable because they measure bulk behavior. Precisely controled neutron irradiation doses (at IPNS), coupled with quantitative diffraction measurements allowed, accurate recording of the amorphization process, via Rietveld profile refinement [9] with Fourier filtering analysis [10] (for modeling of amorphous fraction).

Neutron irradiation results in uranium fission into energetic fragments producing amorphous zones. The volume fraction of amorphous material increases exponentially with dose, and amor- 
phization is complete by a dose of 0.38 displacements per $\mathrm{U}$ atom (dpa) for both alloys (shown for $\mathrm{U}_{3} \mathrm{Si}$ in Figure 1). In each case, a density change from undamaged to amorphous material generates lattice strain in the undamaged fraction. Initially, the lattice strain (tensile for $\mathrm{U}_{3} \mathrm{Si}$ and compressive for $\mathrm{U}_{3} \mathrm{Si}_{2}$ ) increases linearly with amorphous volume fraction (see Figure 2). At higher irradiation levels, however, plastic flow in the amorphous volume fraction of $\mathrm{U}_{3} \mathrm{Si}$ relieves strain in the remaining crystalline volume fraction, following an appropriate rate law (see legend in Fig. 2).

NPD patterns of partially amorphized $\mathrm{U}_{3} \mathrm{Si}$ and $\mathrm{U}_{3} \mathrm{Si}_{2}$ are quite complex. In addition to Bragg scattering from remaining crystalline portion, and oscillatory scattering characteristic of amorphous material, there is significant diffuse scattering associated with each Bragg peak, due to scattering interference between the crystalline and amorphous materials. For $\mathrm{U}_{3} \mathrm{Si}$ this contribution appears to be symmetric about the Bragg position, while in $\mathrm{U}_{3} \mathrm{Si}_{2}$ it is distinctly asymmetric.

Amorphous zones (roughly spherical regions of amorphized material) produced by neutron irradiation generate displacement fields which shift atoms from their ideal positions. These displacements need not have a direct correlation with the crystalline lattice. This phenomenon results in an additional scattering profile whose maxima are closely, but not directly, correlated with Bragg positions. The positions of Bragg peaks at intermediate doses are controlled by the elastic constants for crystalline $\mathrm{U}_{3} \mathrm{Si}$ and $\mathrm{U}_{3} \mathrm{Si}_{2}$, while positions for diffuse scattering maxima are more subtly controlled. Through the application of standard theories for diffuse scattering [11], we have developed a means for quantifying such factors as the size of the amorphous zones, the magnitude of the diffuse scattering contribution, and crystallographic direction-dependent variations in the displacement of the diffuse scattering component from associated Bragg peaks (Figure 3).

Currently underway is a study of the re-crystallization of $\mathrm{U}_{3} \mathrm{Si}$ and $\mathrm{U}_{3} \mathrm{Si}_{2}$ by vacuum anneals at progressively higher temperatures. These data illustrate gradual evolution of the short- to intermediate-range amorphous structure prior to re-crystallization [12].

\section{Acknowledgements}


Work performed at Argonne National Laboratory is supported by the U.S. Department of Energy, Office of Basic Energy Sciences, under Contract No. W-31-109-ENG-38.

\section{References}

1. G.L. Hofman, J. Nucl. Mater., 140 (1986) 256.

2. R C. Birtcher, C.W. Allen, L.E. Rehn and G.L. Hofman, J. Nucl. Mater., 152 (1988) 73.

3. R.C. Birtcher, L.M. Wang, C.W. Allen and R.C. Ewing, in: Proc. XIIth Int. Congress on Electron Microscopy, 1990, ed. L.D. Peachey and D.B. Williams (San Francisco Press) p.534.

4. R.C. Birtcher, J.W. Richardson, Jr. and M.H. Mueller, J. Nucl. Mater., 230 (1996) 158.

5. R.C. Birtcher, J.W. Richardson, Jr. and M.H. Mueller, J. Nucl. Mater., 244 (1997) 251.

6. J.D. Jorgensen, J. Faber, Jr., J.M. Carpenter, R.K. Crawford, J.R. Hauman, R.L. Hitterman, R. Kleb, G.E. Ostrowski, F.J. Rotella and T.G. Worlton, J. Appl. Crystallogr., 21 (1989) 321.

7. R.C. Birtcher, T.H. Blewitt, M.A. Kirk, T.L. Scott, B.S. Brown and L.R. Greenwood, J. Nucl Mater., 108\&109 (1982) 3.

8. A. Taylor, J.R. Wallace, E.A. Ryan, A. Phillippides and J.R. Wroedel, Nucl. Instrum. Meth., 189 (1981) 261.

9. H.M. Rietveld, J. Appl. Crystallogr., 2 (1969) 65.

10. J.W. Richardson, Jr. and J. Faber, Jr., Advances in X-Ray Anal. 29 (1986) 143.

11. S.-K. Chan, J.W. Richardson, Jr. and R.C. Birtcher, to be published.

12.J.W. Richardson, Jr., R.C. Birtcher and R.R. Thomas, to be published. 


\section{Figure Captions}

Figure 1. Small portion of the neutron diffraction pattern for $\mathrm{U}_{3} \mathrm{Si}$ at different levels of irradiation. This illustrates the anisotropic strain induced by amorphization, and the fully amorphous silicide produced after 0.38 dpa damage.

Figure 2. Lattice strain in $\mathrm{U}_{3} \mathrm{Si}$ resulting from neutron irradiation. Strain follows new rate law as plastic flow of amorphous fraction reduces the impact of the density change on amorphization.

Figure 3. Illustration of the quality of fit acheived with a defect model accounting for diffuse scattering associated with each of the crystalline Bragg peaks in $\mathrm{U}_{3} \mathrm{Si}_{2}$. This fit is for the (311) reflection. 


\section{Estimation of the length of this paper}

a) Title, authors, affiliations and 157-word abstract

177 words

b) Three figures, fitting a single column

450 words

c) Manuscript text

655 words

d) References (12)

201 words

Total: 1483 words

For two printed pages: 1600 words 


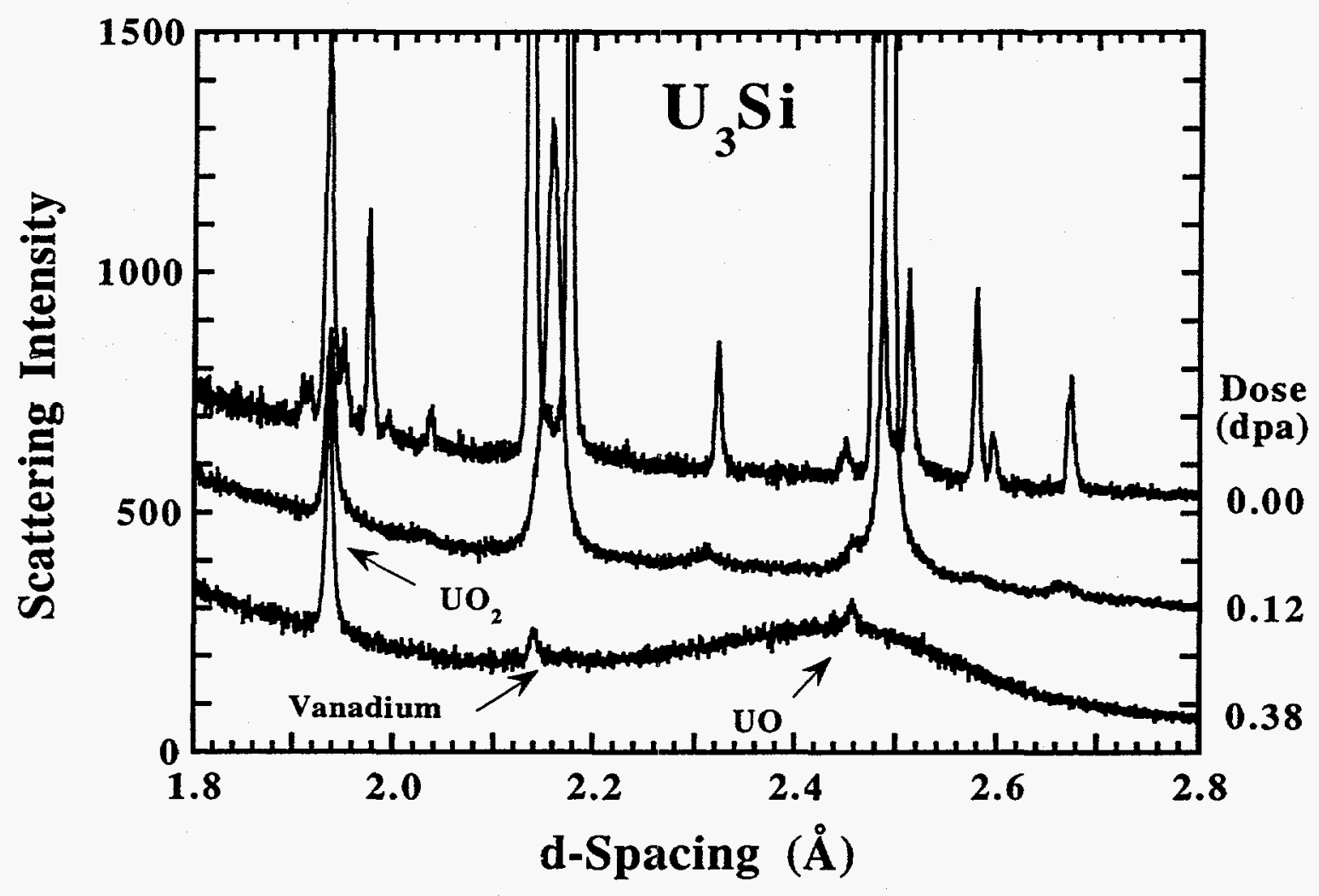

fig. 1 


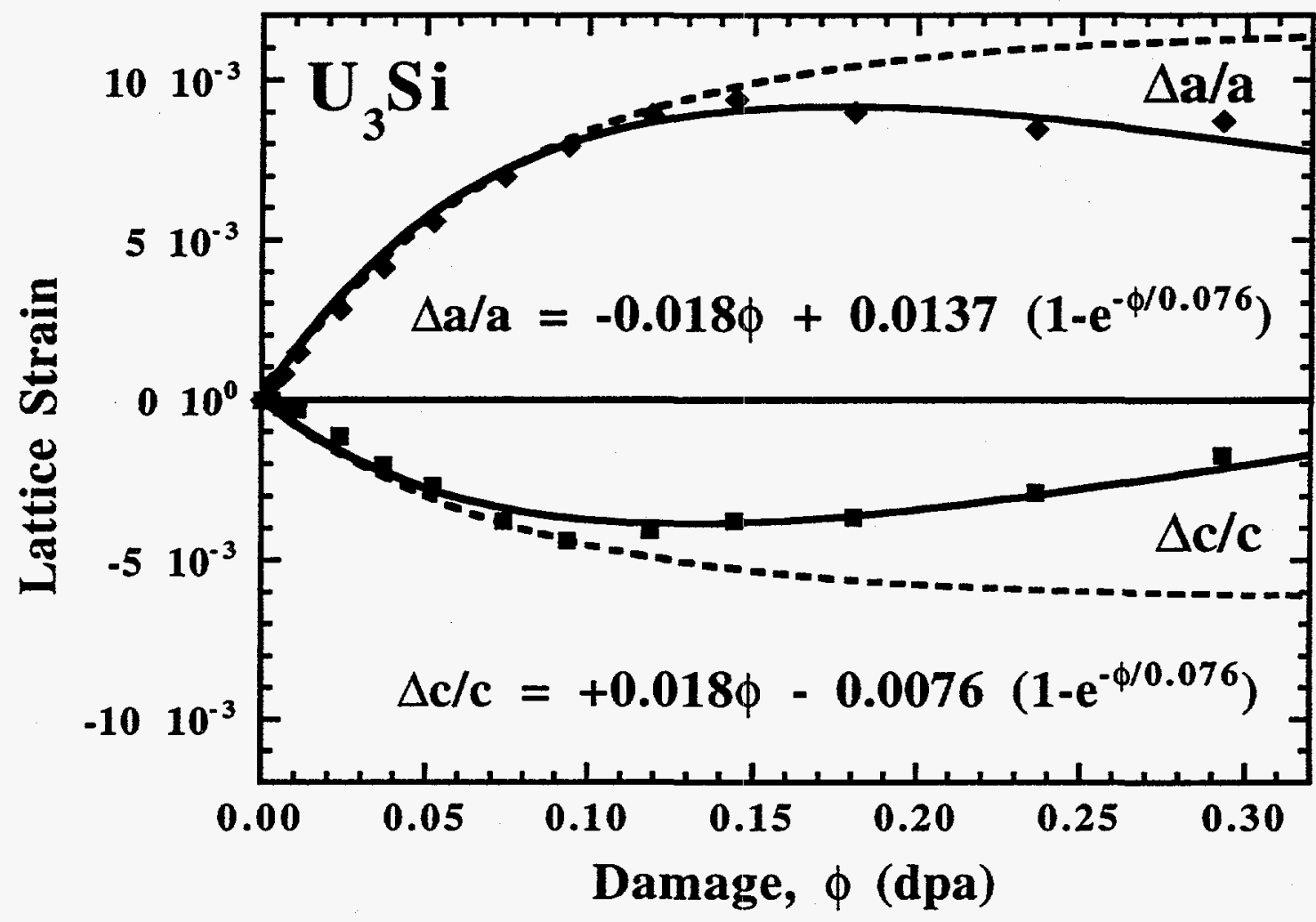

fig. 2 


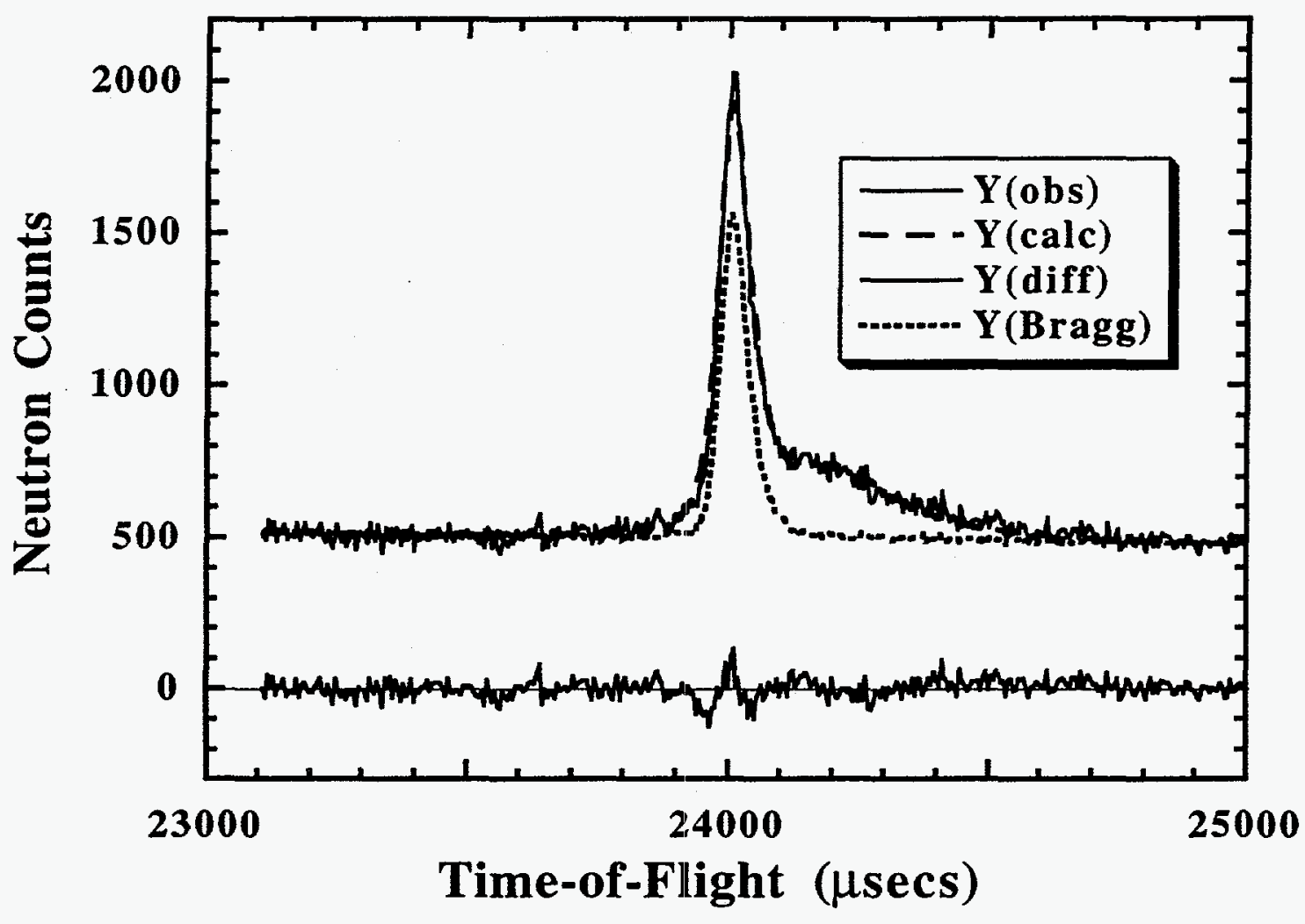

fia 3 